\title{
Production of Valuable Materials from Sago Bark Using Subcritical Water Treatment
}

\author{
Nurhusni Amin', Nordin Sabli',2,*, Shamsul $\operatorname{Izhar}^{1}$ \& Hiroyuki Yoshida1 \\ ${ }^{1}$ Department of Chemical and Environmental Engineering, Faculty of Engineering, \\ Universiti Putra Malaysia, 43400 UPM Serdang, Selangor, Malaysia. \\ ${ }^{2}$ Institute of Advance Technology (ITMA), Univerisiti Putra Malaysia, 43400 UPM Serdang, \\ Selangor, Malaysia.
}

\begin{abstract}
Sago bark is generated as by-product from sago starch industries. Malaysia as one of the biggest exporter of sago starch produces a lot of sago bark wastes which are now burned on-site and underutilized. This study aims to apply subcritical water as a green solvent for hydrolysis of sago bark in order to obtain the value-added products. Inner and outer layers of sago bark were subjected to subcritical water treatment at $180{ }^{\circ} \mathrm{C}$ to $320{ }^{\circ} \mathrm{C}$ for 5 minutes. Inner layer showed higher yield of total organic carbon and total sugar at $210^{\circ} \mathrm{C}$ than the outer layer, 0.40 and $0.67 \mathrm{~g} / \mathrm{g}$-dry sample respectively. Both layers had generated similar types of monosaccharides and inner layer showed extremely better yield of glucose, xylose and arabinose with the value of $0.125,0.123$ and $0.019 \mathrm{~g} / \mathrm{g}$-dry SB, respectively. Six organic acids were identified and were most favored to produce at a higher temperature. The increasing temperature had led to an apparent tar yields, $\sim 0.40 \mathrm{~g} / \mathrm{g}$-dry SB and a huge drop of solid residues, $\geq 75 \%$. In general, the inner layer was more susceptible to subcritical water treatment than the outer layer with evident yields of all products produced.
\end{abstract}

Keywords: subcritical water; sago bark; sugars; organic acid; tar.

\section{INTRODUCTION}

Lignocellulosic biomass waste is a cheap and huge resource found across the world that has the capability to sustain the production of biofuels and biochemicals. Being a non-edible portion of the plant, lignocellulosic biomass has gained growing attention as these materials are ascribed as carbon neutral [1] and the perfect equivalent to petroleum. These materials are generated from natural source of carbon dioxide, water, and sunlight through biological photosynthesis. Therefore, when these materials are used as resources for bioenergy/biofuel, burned or processed into fine chemicals, a close carbon cycle will be maintained with zero net carbon emission to the earth's atmosphere [2], [3]. Lignocellulose biomass chemically composed of cellulose and hemicellulose that are bound together by lignin [4], [5]. Pretreatment and hydrolysis on both cellulose and hemicellulose can convert these long chain sugar polymers into intermediate products and further used for biofuels or other industrially important products [6]. Sago bark (SB) represents one of the renewable sources of lignocellulose biomass. Annually, commercial sago starch industry in Malaysia discards more than 20, 000 ton of SB as a by-product [7]. These barks are left in sago mill surroundings as flooring materials or burnt off. These practices caused wastage of valuable materials, posed serious environmental issues, i.e. river and air pollution, and exposing both neighboring residence and labors to hazards [8]. Thus, reduction and utilization of this waste into value-added substances is of paramount importance pertinent to its large content of cellulose and hemicellulose compositions.

There are lots of hydrolysis techniques and technologies applied to cleave and dismantle the complex and recalcitrant structure of lignocellulosic biomass. Those methods include acid hydrolysis, enzymatic hydrolysis, and microwave-assisted dilute acid pretreatment as the latest technique applied on SB [7], [9], [10]. However, those techniques are ascribed as environmentally unacceptable, time-consuming and might also cause overheating by resonance phenomena in the microwave, respectively [11], [12]. In light of the disadvantages, subcritical water (SCW) has increasingly gained attention as both green solvent and friendly reactive medium for a variety of applications [13].

$\mathrm{SCW}$ is described as hot water that lies between temperatures of 100 to $374{ }^{\circ} \mathrm{C}$ under high pressure, $\sim 22.4 \mathrm{MPa}$ to maintain water in the liquid state. It is considered as an environmentally friendly and economic solvent by which only water is used as a solvent. The advantages of SCW are amplified with its increasing temperatures such as a decrease in surface tension, viscosity and dielectric constant, thus, allow it to dissolve hydrophobic substances. In addition, SCW can also act as acid or base catalyst during reactions due to the three magnitude increases of water dissociation constant than that in ambient temperature [14], [15]. One of the most advantages of SCW on biomass samples is that no pretreatments such as drying and crushing are needed. SCW as reactant mainly leads to hydrolysis reaction on biomass to sugars [16].

There are very minimal efforts have been done on SB wastes either industrially or in research institutions [17] that rooted from no clear new technology can be adapted for alternative sago bark utilization [18]. As such, SCW treatment which is 
known as a green solvent done in this study should contribute a new idea in this field. To the best of our knowledge, there is no previous study done on SB under SCW temperature range. Hence, this study is directed primarily towards understanding the effect of SCW temperature on different layers of SB. Though the constitutions of bark layers are closed to each other, but the contents are varied. The hydrolysates obtained from different layers and the yields of various products produced are examined and compared, respectively.

\section{EXPERIMENTAL SECTION}

\subsection{Materials}

Sago palm trunk was purchased from a local sago plantation in Melaka, Malaysia. Sago trunk was debarked manually by removing the pith portion. The bark was then divided into inner (light brown) and outer (dark brown) layers which were specified as $7-12 \mathrm{~mm}$ and 1 - $5 \mathrm{~mm}$ from outside circumference respectively. The layers were chopped into small pieces and stored in a freezer of different sealed plastic bags for further experiments.

\subsection{Materials Characterization}

\subsubsection{Moisture Content}

Wet inner and outer layers of sago bark were weighed $(\sim 3 g)$ and put into separate beakers before drying in a dryer set at $80^{\circ} \mathrm{C}$. They were weighed for a week until final constant weights were achieved. The moisture content was calculated using equation (1) [19]. The moisture content values were used to find the dry weights in equation (2):

$$
\mathrm{MC}(\%)=\frac{\text { Initial weight of SB-final weight of SB }}{\text { Initial weight of SB }} \times 100
$$

$$
\text { DW }(\mathrm{g})=\text { Weight of charged SB }-\left(\frac{\mathrm{MC}}{100} \times \text { Weight of charged SB }\right)
$$

Where MC stands for moisture content while DW for dry weight.

\subsubsection{Chemical Composition}

Inner and outer layers of SB were ground to pass through a 40mesh screen size. All of the procedures were done according to TAPPI standard methods. However, it should be noted that Institute of Tropical Forestry and Forest Products, Universiti Putra Malaysia (INTROP-UPM) has modified the procedure used for the standards [20], [21].

\subsubsection{Ash Content}

Ash content calculated based on the difference between the initial and final weights. About $3 \mathrm{~g}$ of fresh samples were prepared on three different porcelain plates before heated in a furnace (Nitto Kagaku, APC-103) to reach a temperature set at $800{ }^{\circ} \mathrm{C}$. The samples were left in the furnace for 2 hours until the combustion completed. After finished, the samples were let to cool down in a desiccator at room temperature before weighed and calculated the yields as in equation (3). The average values were used and recorded.

$$
\text { Yield of ash (g/g-dry SB) }=\frac{\text { Weight of ash }(\mathrm{g})}{\text { DW }(\mathrm{g}-\text { dry SB })}
$$

\subsection{SCW Treatment}

The reactor used was a stainless-steel tube with a total volume of $6.64 \mathrm{~cm}^{3}$ capped with Swagelok fitting on both ends. $1.0 \mathrm{~g}$ sago bark was weighed, and $4.0 \mathrm{ml}$ deionized water were charged into the tube before being purged with argon gas to force air out, and the cap was tightened prior reaction. It was then immersed in a thermal bath for 5 min to undergo SCW treatment. The SCW treatment was carried out in two types of batch lab-scale thermal bath. Preheated oil bath was used for temperatures between 100 to $180{ }^{\circ} \mathrm{C}$ whilst, preheated salt bath for temperatures 200 to $360{ }^{\circ} \mathrm{C}$ [22]. The thermal bath mixing speed was set constant at $10 \mathrm{rpm}$ for all temperatures. Important to note that, the mentioned $5 \mathrm{~min}$ reaction time, includes the heating-up time and was proven from previous study, the heating-up rate can reach a steady-state condition in less than $50 \mathrm{~s}$ [23]. After reaching the desired time, the reactor was removed and immediately quenched by soaking in a water bath to stop the reaction. The steam table was used to estimate the equilibrium pressure for each temperature applied as explained elsewhere [24]. All experiments were done following the same procedures. Only reaction temperature set was changed at a time accordingly.

\subsubsection{Separation of Produced Phases after Sub-critical Water Reaction}

After SCW treatment, the reactor content was classified and differentiated into three phases: water-soluble (WS), acetonesoluble (AS) and residual solid (RS) phases. Firstly, the reactor content was transferred into a test tube and centrifuged at 4000 rpm using a (KUBOTA, 2410) centrifuge for $5 \mathrm{~min}$. The $\mathrm{pH}$ of WS phase in the test tube was measured using digital $\mathrm{pH}$ meter (Horiba Ltd F-52) before it was collected into a stock bottle. Deionized water was added adequately into the reactor tube and shaken vigorously to recover the remaining WS components. Then, it was transferred into the same test tube. Tube mixer was used to thoroughly mix the content in the test tube before centrifuged, and WS phase was then collected and transferred into the same stock bottle. These steps called washing steps, were done repeatedly until all WS phase discharged from the reactor became colorless. After the reactor tube was cleaned, some amount of deionized water was added into the test tube which only a RS phase remained. The same steps of washing similarly as the recovery of WS phase from the reactor tube were repeated until colorless. The collected WS phase in a stock bottle was later filtered using $0.45 \mu \mathrm{m}$ membrane filter (PALL, GN-6 Metricel, Mexico) and final total volume was recorded. The filtrate was kept in the refrigerator for further analysis. 
Acetone was used to recover the water-insoluble tar or acetone soluble, AS. Before adding some amount of acetone into the reactor, the reactor and test tube were priory dried in a $60{ }^{\circ} \mathrm{C}$ dryer. Similarly, acetone washing was done repeatedly until colorless. The collected AS was then filtered using $0.20 \mu \mathrm{m}$ polytetrafluoroethylene (PTFE) syringe filter (CHROMAFIL, Macherey-Nagel, Germany). Tar amount was measured by weight after evaporation of the acetone completed. Finally, the remaining RS was left to dry in a fume hood at room temperature to a constant weight.

\subsubsection{Analysis}

TOC analyzer (Shimadzu TOC-VCPH, Shimadzu Co. Japan) was employed to measure total organic carbon (TOC) [22]. A UV-visible spectrophotometer (Shimadzu UV-160, Shimadzu Co. Japan) was used with slight modification to measure total sugar following the phenol-sulfuric acid method [25], [26]. The concentration of total sugar was made equivalent to glucose and calculated based on external calibrated glucose standard solution with different concentrations (10 - $100 \mathrm{ppm})$.

Quantitative analysis of sugar products was analyzed using high performance liquid chromatography, HPLC [22]. The HPLC unit is equipped with a pump (Jasco, PU-2080plus), vacuum degasser (Jasco, DG-2080-53) and an auto sampler (Jasco, AS-2053plus), which connected to a refractive index, RI detector (Jasco, RI-2031plus, Jasco Crop. Japan). One column (Hi-Plex H, $300 \times 7.7 \mathrm{~mm}$, Agilent Technologies, Germany) is used with temperature set at $50{ }^{\circ} \mathrm{C}$, and deionized water as the mobile phase at a flow rate of $0.3 \mathrm{mLmin}^{-1}$. The six standard sugars used were cellotriose (99\%, Kanto Chemical, analytical grade), 98\% D (+) cellobiose (98\% Sigma Aldrich, analytical grade), D (+) glucose (anhydrous), xylose, fructose and arabinose (99\%, glacial).

The concentration of organic acids was determined using organic acid HPLC system (Shimadzu LC-6A, Shimadzu Co. Japan) [27] equipped with two ion-exclusion chromatography columns in series (Shim-pack SCR-102H, $8 \mathrm{~mm} \times 300 \mathrm{~mm}$, Shimadzu Co. Japan) and were placed in a $45^{\circ} \mathrm{C}$ column oven (Shimadzu, CTO-10AC). The detection used electroconductivity detector (Shimadzu CDD-6A, Shimadzu Co. Japan). The mobile phase was $0.951 \mathrm{gL}^{-1}$ of p-toluenesulfonic acid, while the buffer was a mixture of $0.951 \mathrm{gL}^{-1}, 0.029 \mathrm{gL}^{-1}$ and $0.4185 \mathrm{gL}^{-1}$ of p-toluenesulfonic acid, EDTA and Bis-Tris respectively. Both were pumped into the column with the same $0.8 \mathrm{ml} / \mathrm{min}$ flow rate. Acetic acid (99\%, glacial), formic acid, DL malic (99\%), levulinic acid (100\%), succinic acid and lactic acid were all from R\&M (analytical grade) were used as standards in this work All of the product yields were calculated as the following equation (4):

$$
\mathrm{P}(\mathrm{g} / \mathrm{g}-\mathrm{dry} \mathrm{SB})=\frac{\text { Weight of product }(\mathrm{g})}{\mathrm{DW}(\mathrm{g}-\text { dry } \mathrm{SB})}
$$

Where $\mathrm{P}$ represents yield of TOC, total sugar, tri-, di-, and monosaccharides, tar and residual solids.

\section{RESULTS AND DISCUSSIONS}

\subsection{Chemical Composition of SB}

Based on the chemical composition (Table 1), generally the inner and outer layer of SB comprised of four main components which are extractives, cellulose, hemicellulose and lignin. Although both layers of the SB came from the same tree, it is observed that the dominant components present in each layer are different. Significant composition of extractives and cellulose are found in the inner layer, while lignin in the outer layer. The varied distribution and composition of lignocellulosic components in different layers of SB are closely related to its functions on the palm tree. The rigid structure of lignin found on the outer layer serves as a shield against rapid microbial and fungal destruction to the palm [28]. On the other hand, cellulose in the inner layer (in large forming a vascular system) functions to provide strength and water [29]. Meanwhile extractives serve as metabolism intermediates and also as nutrient storages [28], [30]. It has also been emphasized that the composition of biomass components may vary depending on the type, plant species, source of biomass and even the different parts of the same plant [31].

However, the biomass fractions obtained in this study are quite different with the SB composition reported previously [7], [32] on certain components, but are still quantitatively considerable. The discrepancies arise between the data might due to the variations of plant ages, storage times and temperatures, tissue types and both cultivation and harvesting conditions [33]. In particular, the scattering of data is also influenced by the differences in the methods used for characterization such as the extent of extractives removal during treatment with different solvents and hence, may interfere in the quantification of polysaccharides and lignin [34].

\subsection{TOC (WS Phase)}

As the most important measure to ensure the decomposition of SB in SCW treatment, TOC was investigated. The effect of reaction temperature at constant 5 min reaction time on the TOC is shown in Figure 1. Initially, very little amount of organic carbon $(<1 \%)$ could dissolve in water at room temperature for inner and outer layers which were contributed from the non-structural carbohydrate extractives [35] available in the bark. However, SCW treatment had multiplied the SB solubility in water $5-8$ times more which indicates that SCW has successfully hydrolyzed complex carbon chain of polysaccharides into water soluble fractions. Besides, a significant yield of TOC was obtained from inner than the outer layer. The highest yield recorded were $0.40 \mathrm{~g} / \mathrm{g}$-dry SB ( $\mathrm{T}=210$ ${ }^{\circ} \mathrm{C}$ ) and between $0.16-0.17 \mathrm{~g} / \mathrm{g}$-dry $\mathrm{SB}\left(\mathrm{T} \geq 210^{\circ} \mathrm{C}\right)$ for inner and outer layer respectively. This result indicates that about $40 \%$ of organic carbon from inner layer was recovered in the water phase which is equivalent to $\sim 20$ points more than that of outer layer. 


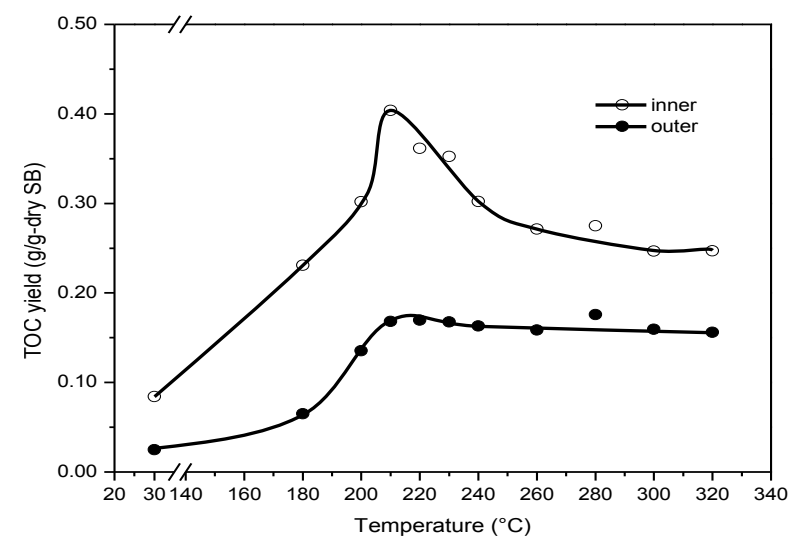

Figure 1 Effect of reaction temperature on TOC yield (Reaction time: $5 \mathrm{~min}$ )

Table 1 Chemical composition of SB

\begin{tabular}{lcccccc}
\hline $\begin{array}{l}\text { Component } \\
\text { wt\% }\end{array}$ & \multicolumn{2}{c}{ This study } & & & & \\
\cline { 2 - 3 } & $\begin{array}{c}\mathrm{SB} \\
\text { (inner) }\end{array}$ & $\begin{array}{c}\text { SB } \\
\text { (outer) }\end{array}$ & $\begin{array}{c}\text { Ethaib et } \\
\text { al.[60] }\end{array}$ & $\begin{array}{c}\text { Mohamad et al. Hardwood Softwood } \\
{[32]}\end{array}$ & & \\
\hline Extractives & 16.6 & 9.99 & N/A & N/A & $0.1-7.7$ & $0.2-8.5$ \\
Holo-cellulose & 57.5 & 42.21 & N/A & N/A & $71-89$ & $60-80$ \\
a-cellulose & 33.94 & 22.22 & 40.79 & 44.13 & $31-64$ & $30-60$ \\
Hemicellulose & 23.39 & 20.03 & 22.32 & 21.09 & N/A & N/A \\
Lignin & 12.32 & 28.33 & 25.85 & 23.30 & $14-34$ & $21-37$ \\
Ash & 1.89 & 2.94 & 2.33 & 1.53 & N/A & N/A \\
\hline
\end{tabular}

After a maximum reached $210{ }^{\circ} \mathrm{C}$, the TOC yield was then started to level off for inner while almost plateau trend was shown by outer layer with further increase of temperature. The steep TOC reduction on inner with temperature was owing to its higher hemicellulosic content than the outer layer (refer Table 1) that is prone to degrade quickly at high temperature. Besides, the drop of TOC value at high temperature also indicated the decomposition of soluble products into gases product had taken place. The weakening of hydrolysis reaction and the dominancy of gasification reaction with temperature [22] also helped in promoting rapid polysaccharides degradation of inner than outer layer into gaseous by-product i.e. carbon dioxide [36], [37].

\subsection{Total Sugars (WS Phase)}

To extract sugars from lignocellulosic biomass, firstly it must undergo hydrolysis reaction. Hydrolysis reaction will lead to the cleavage of ether and ester bonds in polysaccharides by the inclusion of water molecule for every broken linkage, thus results in the production of simpler sugars [38]. However, the present of the third most abundant component, lignin in the lignocellulosic biomass complicates further the process. The lignin must be broken down so that the polysaccharides are reachable to hydrolysis [39]. Besides, by having different degree of polymerization, DP, hemicellulose is easier to hydrolyze than cellulose in SCW, hence hydrolyzed at different temperatures [37], [40]-[42]. Therefore, this leads to the selection of reaction temperature between 180 to $320{ }^{\circ} \mathrm{C}$ in this study. Two parameters were kept constant, time and solid to water, S/W ratio, to find out the effects of temperature on different layers of SB in producing valuable substances. The ideal retention time $(5 \mathrm{~min})$ and $\mathrm{S} / \mathrm{W}$ ratio (1:4) with slight modification were chosen based on SCW hydrolysis researches done previously on biomass [19], [22], [43].

Since polysaccharides were the primary components of SB, a high amount of soluble carbohydrates obtained after SCW treatment could be expected. Figure 2 shows the effect of temperature on the yield of total sugar after 5 min reaction time and its relationship with ion product constant of water. The total sugar yield increased with increasing temperature and reached the highest value of 0.67 and $0.27 \mathrm{~g} / \mathrm{g}$-dry SB at $210{ }^{\circ} \mathrm{C}$ for inner and outer layers respectively, while subsequently dropped was observed above $210^{\circ} \mathrm{C}$. High sugar yield observed at a lower temperature is strongly associated with hemicellulose decomposition. Hemicellulose is found to easily solubilized and hydrolyzed at $180{ }^{\circ} \mathrm{C}$ while at $230{ }^{\circ} \mathrm{C}$, almost $100 \%$ hemicelluloses of various woods were hydrolyzed [37]. In addition, significant sugar yield obtained from the inner layer is in accordance with its higher hemicellulose content than outer layer.

Rapid decomposition of both layers into sugar was at peak corresponded to the maximum ionic constant of water, $\mathrm{K}_{\mathrm{w}}$ between $200-250{ }^{\circ} \mathrm{C}$. This proved strong hydrolysis power at this condition. Water dissociates at higher degree at subcritical condition thus, producing higher concentration of hydronium ion $\left(\mathrm{H}_{3} \mathrm{O}^{+}\right)$which is three magnitude higher than that of ambient condition. At such condition, hydrolysis of macromolecules such as polysaccharides into smaller molecules is enhanced [45]. On the other hand, higher conversion of sugar into degraded products and the dominancy of pyrolysis reaction explain the dropped of sugar yield observed for both layers with temperature. Sugar decomposed rapidly to degraded products such as 5-HMF and furfural at high temperature and also, may cause some thermally-labile compound degrade after released from the sample matrix [46], [47].

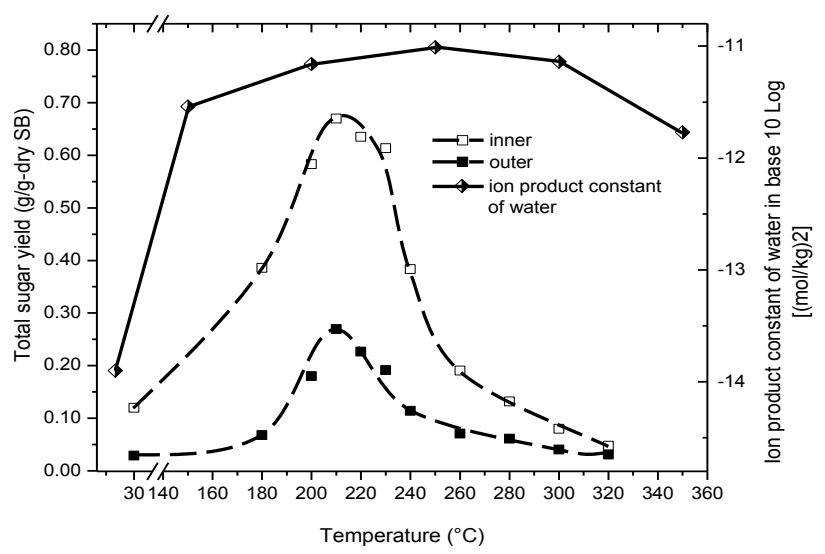

Figure 2 Effect of reaction temperature on total sugar yield and its relationship with ion product constant of water (Reaction time: $5 \mathrm{~min}$ ) 


\subsection{Oligosaccharides and Tri-Di-, Monosaccharides (WS Phase)}

Based on the ratios of cellulose and hemicellulose on different layers of SB used in this study, it was assumed that about $57.3 \%$ and $42.3 \%$ of SB wastes could be used as sources of saccharides from inner and outer layer respectively. Total sugar itself is not enough to provide details on saccharides obtained after SCW treatment, thus HPLC analysis were done on WS phase collected to have a clearer vision on hydrolysis products. Figure $3 \mathrm{a}$ and $3 \mathrm{~b}$ show the yield of different sugars from inner and outer layers respectively. Due to the limitation of identifying all peaks appeared on HPLC chromatogram (data not shown), the peak areas of each saccharide are calculated and taken into account. The sum up of unknown peak areas were categorized as oligosaccharides while the known peak areas (based on standard samples) as tri-di-monosaccharides as shown in Figure $3 a(i)$ and $3 b(i)$.

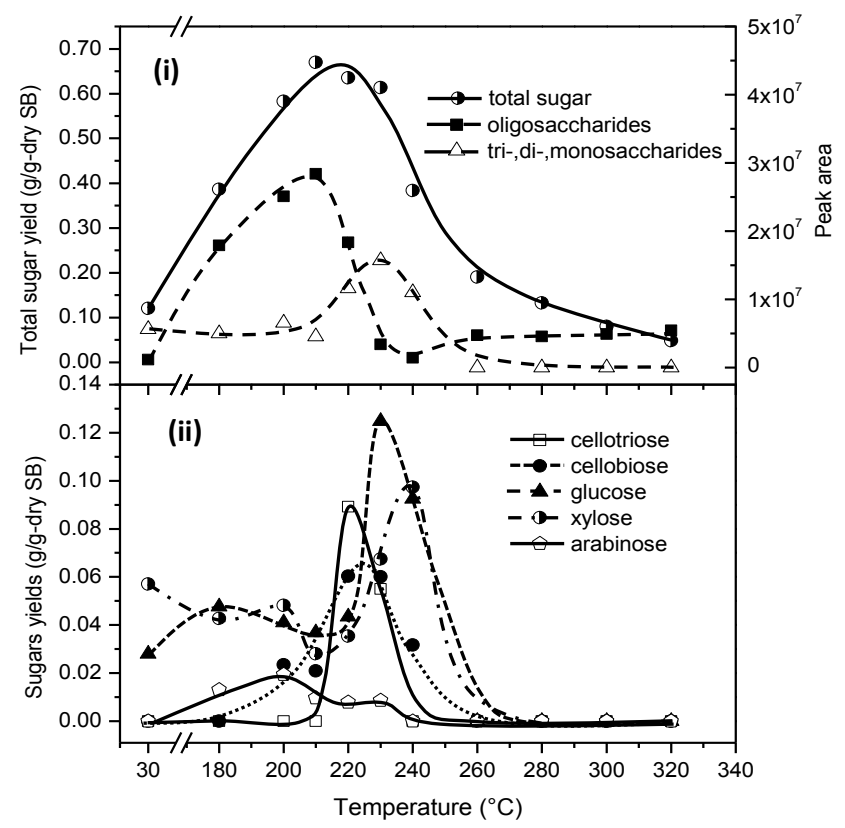

Figure 3a Sugar peak areas (i) and sugar yields (ii) for inner layer at different reaction temperature (Reaction time: $5 \mathrm{~min}$ )

Referring to Figure 3a(i) and 3b(i), both layers of SB were first hydrolyzed into oligosaccharides at around $200{ }^{\circ} \mathrm{C}-210{ }^{\circ} \mathrm{C}$ then, it decomposed further into tri-, di-, monosaccharides at higher temperature, $230{ }^{\circ} \mathrm{C}-240{ }^{\circ} \mathrm{C}$. However, the increasing of reaction temperature $>240{ }^{\circ} \mathrm{C}$, caused tri,-di-, monosaccharides content in WS phase to fall and disappear. In brief, hemicellulose and cellulose were initially hydrolyzed to higher DP of oligosaccharides and sequentially be cut to lower DP oligosaccharides. Then, it will hydrolyze to monosaccharides when presuming there is no further decomposition of saccharides [48]. The behavior of the results obtained in this study is also agreed with several researches done previously [49], [50]. Besides, there are significant oligoand tri-, di-, monosaccharides generated from inner than outer layer according to areas of peak generated. This deduced that inner layer is more susceptible to SCW hydrolysis.
Unlike the tri-, di-, and monosaccharides, the oligosaccharides for both layers did not fall zero at elevated temperature, >240 ${ }^{\circ} \mathrm{C}$ but remained constant and showing plateau trend. This was high probably that cellulose hydrolysis had happened on this range of temperature [37], [51]. However, due to the rapid decomposition at higher temperature, the cellulose sugars produced i.e. cellotriose, cellobiose and glucose had simultaneously decomposed into secondary products. As explained elsewhere, sugars decomposed rapidly to degraded products i.e. organic acids, erythrose, glycolaldehyde, furfural, 5-HMF etc. at high temperatures [44], [46]. Moreover, the highest total sugar yields for both layers shared the same maximum temperature peak, $210{ }^{\circ} \mathrm{C}$ with those of oligosaccharides. This explained total sugar is strongly correlated with oligosaccharides present in the WS phase as it reacted the most with the strong acid applied, sulfuric acid apart from simple sugars [26], [52].

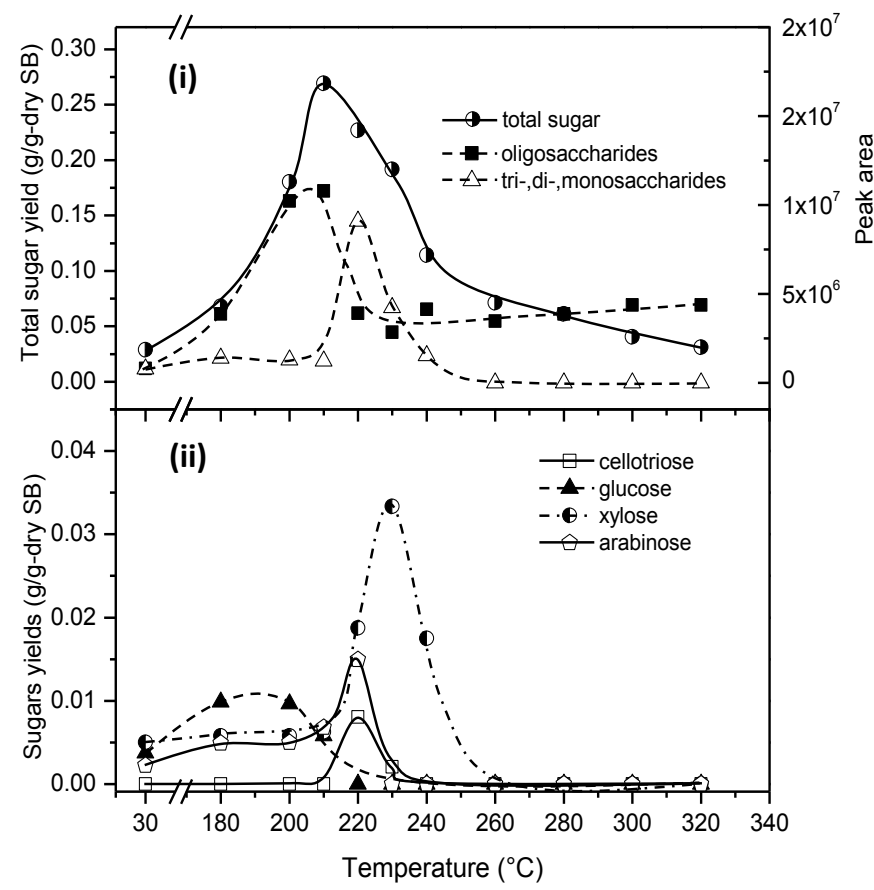

Figure 3b Sugar peak areas (i) and sugar yields (ii) for outer layer at different reaction temperature (Reaction time: $5 \mathrm{~min}$ )

General observation upon Figure 3a(ii) and 3b(ii) shows inner layer yielded significant amount of sugars than the outer layer. Same products were produced from both layers except for cellobiose, which was not detected from the outer layer. However based on Figure 3a(ii), twice decomposition of glucose and xylose were detected throughout the reaction temperature, whereby the yield of glucose and xylose were reduced at lower temperature up to $210{ }^{\circ} \mathrm{C}$, before both rise again. The rapid decomposition of originally present free sugars i.e. xylose and glucose (see Figure $3 \mathrm{a}(\mathrm{ii}), 30^{\circ} \mathrm{C}$ ) which also ascribed as heat labile substances, over hemicellulose hydrolysis in inner layer explains the first declined trend obtained. This is further supported by a study [45], stating that the free glucose originally present in the sample might partly 
contribute to the presence of glucose in the hydrolysate. At the same time, the appearance of arabinose [53], [54] confirmed that the hydrolysis of hemicellulose had also occurred at this condition. This indicates that hemicellulose is easier to hydrolyze at lower temperature.

The yield of xylose from inner layer showed similar trend with that of glucose, but slightly lower in value. The highest yield of both glucose $\left(230{ }^{\circ} \mathrm{C}\right)$ and xylose $\left(240{ }^{\circ} \mathrm{C}\right)$ were 0.125 and $0.123 \mathrm{~g} / \mathrm{g}$-dry SB respectively, before both drastically dropped with further increase temperature. Meanwhile, arabinose showed faster decomposition with temperature after reaching a maximum yield of $0.019 \mathrm{~g} / \mathrm{g}$-dry SB at $200{ }^{\circ} \mathrm{C}$. This was due to the position of arabinose as side chain in hemicellulose that caused it to liberate faster than other sugars i.e. xylose [55]. On the other hand, the appearance of cellulose sugars i.e. cellotriose and cellobiose between $200-260{ }^{\circ} \mathrm{C}$ suggests that part of cellulose might have started to decompose. Both cellotriose and cellobiose exhibited bell-shaped profiles with maximum yield of 0.089 and $0.060 \mathrm{~g} / \mathrm{g}$-dry SB respectively at $220^{\circ} \mathrm{C}$. Most likely, it was resulted from amorphous domain of cellulose that is more susceptible to hydrolysis at lower temperature since crystalline cellulose required more severe condition to disrupt [56]-[58].

Furthermore, the profile trends of saccharides produced from outer layer (Figure 3b(ii)) are very much alike with that of inner layer. Hemicellulose sugars were majorly obtained from outer layer which again, concentrated at lower temperature, $\leq 240{ }^{\circ} \mathrm{C}$. The highest yield recorded for glucose, xylose and arabinose from outer layer were $0.001,0.033$, and $0.015 \mathrm{~g} / \mathrm{g}$-dry SB respectively which were much lesser as compared to inner layer. All of monosaccharides sourced from different SB layers had shown reduction when reaction temperature increased beyond $260^{\circ} \mathrm{C}$. Severe condition applied at higher temperature explains the dropped of monosaccharides yields, attributed to the rapid decomposition in forming degraded products. This degradation also implied that the increased of reaction temperature will enhance the competitive pathways of sugar degradation [59].

Basically, all of the resulted monosaccharides in this study are consistent with other researches done on SB using different methods [7], [32], [60]. More interestingly, SB inner layer treated in this study exhibited extremely better yield of monosaccharides in $5 \mathrm{~min}$ as compared when treated with the combination of microwave-acid and enzymatic hydrolysis that required $\sim 72 \mathrm{~h}$ [7]. Thus, it seemingly shows that SCW treatment is more appealing when only water was used as solvent and simpler method applied within shorter time.

\subsection{Organic Acids (WS Phase)}

Organic acid analysis was carried out to confirm the degradation of sugars at high temperature. Figure $4 \mathrm{a}$ and $4 \mathrm{~b}$ show the yield of organic acids at different temperatures for inner and outer layers respectively. Generally, the hydrolysate $\mathrm{pH}$ for both layers became acidic from $\mathrm{pH}$ value 6 to 3 with increasing temperature. The consistency of $\mathrm{pH}$ measurements with the degradation of sugars to organic acids can be inferred from the total sugar and oligo- and tri-, di- , monosaccharides yields reported earlier. Apart from the increased in water $K_{w}$ with temperature, the $\mathrm{pH}$ reduction in this study was proven to also cause by organic acids production hence, this might help in autocatalysis during SCW treatment [58], [61].

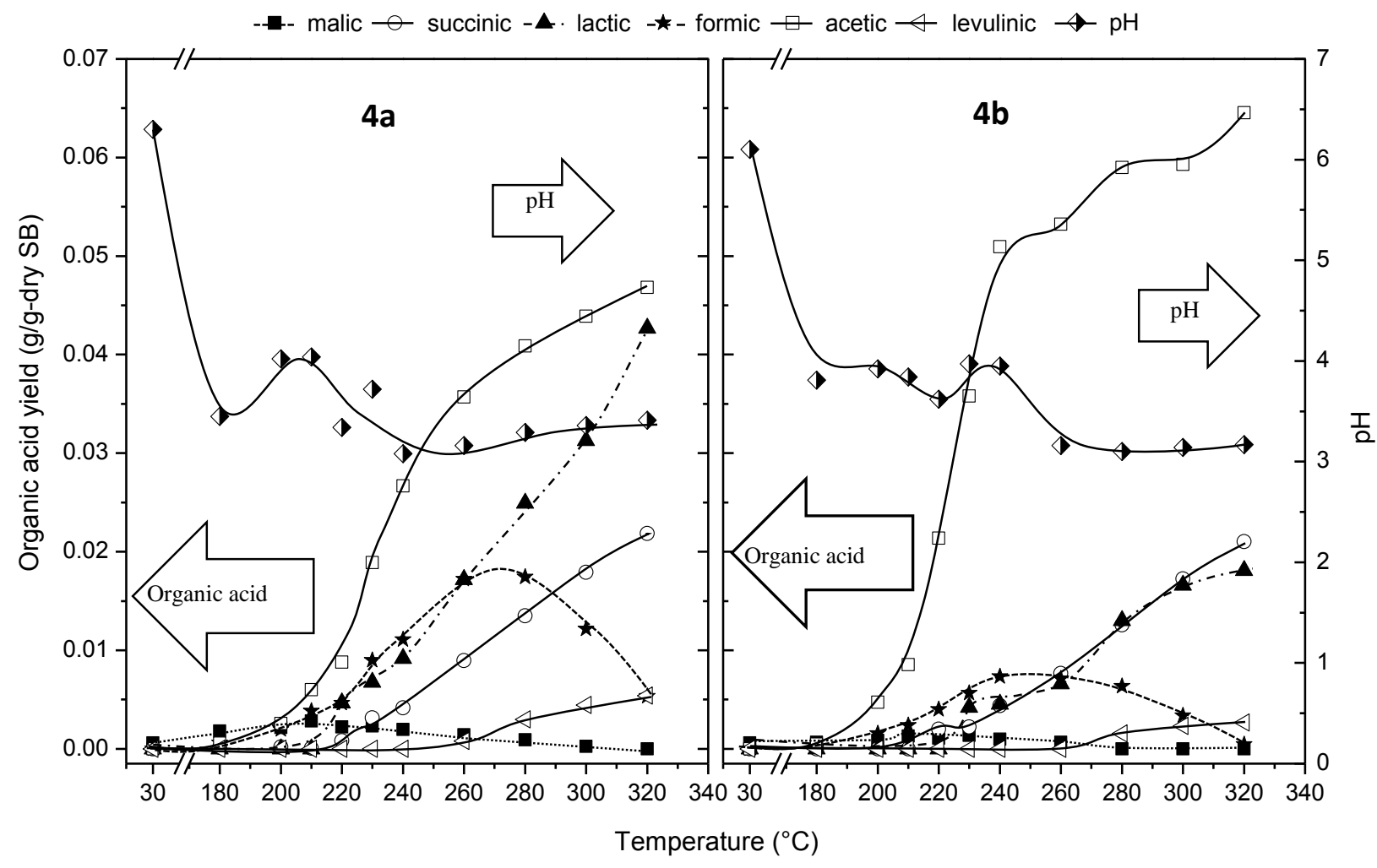

Figure 4 Effect of reaction temperature on the yield of organic acid for inner (a) and outer (b) layers (Reaction time: 5 min) 
Based on Figure 4, inner and outer layers generated same types of organic acids and the yields became more apparent with temperature. The organic acids identified include malic, succinic, lactic, formic, acetic and levulinic acids. Inner layer (Figure 4a) showed higher yields of every organic acid generated except for acetic acid, which was profoundly produced from outer layer (Figure 4b) at $220{ }^{\circ} \mathrm{C}$ onwards. Acetic acid might resulted from hemicellulose decomposition. As stated by Kumar [62], acetic acid is found as one of the hemicellulose side groups that are responsible for the solubility in water apart from pentoses, deoxyhexoses and etc. This also indicated that hemicellulose portion of outer layer liberated more acetic acid, hence explains the lesser hemicellulose sugars yielded from outer layer as compared from the inner layer.

After that, the majorly produced organic acids followed by lactic and succinic acids and both show tendency to rise further with increasing temperature. Conversely, lactic acid was significantly produced from inner than the outer layer. Since lactic acid was mainly generated from cellulose sugars degradation i.e. glucose [63], [64], hence, this is in agreement with the higher cellulose sugars obtained from inner layer as discussed earlier. Formic acid showed somewhat bell-shaped profile trend while malic and levulinic acids showed very negligible yields with temperature, $<0.01 \mathrm{~g} / \mathrm{g}$-dry SB. However, levulinic acid was only appeared at higher temperature of $\geq 260{ }^{\circ} \mathrm{C}$. Identical levulinic acid behavior was also seen with reaction temperature as reported in previous SCW studies [22], [65].

\subsection{Tar (AS Phase) and RS Phase}

AS phase is attributed to tar that are insoluble in water. Tar was defined by Demirbas [66] as a non-aqueous phase that contains insoluble organics of high molecule weight. While, RS is a phase that left after SCW treatment and did not dissolve in either water or acetone in this study. Figure 5 depicted the yield of tar and residual solid for inner and outer layers at various reaction temperature. The yields of tar gradually increased between 180 to $240{ }^{\circ} \mathrm{C}$ for inner and outer layers. However, more significant tar yields were obtained when temperature increased above $240{ }^{\circ} \mathrm{C}$ and reached a maximum yield (at $\mathrm{T} \leq 300{ }^{\circ} \mathrm{C}$ ) of 0.41 and $0.35 \mathrm{~g} / \mathrm{g}$-dry SB for inner and outer layer respectively. This was due to the dominancy of pyrolysis over hydrolysis reaction at higher temperature that caused the production of tar most favoured [22]. The resulted trend of tar yield with temperature in this study was similar to other biomass wastes treated in SCW reported previously [16], [65], [67]. Further increased in temperature however had caused the yield of tar became almost plateau and reduced for inner and outer layer respectively. This was due to the simultaneous secondary decomposition of tar to solid (char) and gases [68].

Nevertheless, the tar yield produced from inner layer was slightly higher than that of outer layer at elevated temperature. Initially, biomass was hydrolyzed into water-soluble products during SCW reaction before undergoing secondary decomposition, producing unstable smaller components i.e. 5HMF, furfural, organic acids etc. [66], [69]. These smaller compounds which ascribed as organic intermediates [70] will further re-polymerize and condense to form high viscosity hydrophobic tar, char and light gases at elevated temperature [37], [69]. In parallel with higher solubilized materials generated from inner layer based on TOC result obtained, this explains the higher yield of tar obtained from inner as compared to the outer layer. In addition, production of tar during reaction at high temperature is contributed from all three main constituents in biomass i.e. cellulose, hemicellulose and lignin which contains hundreds of oxygenated compounds with various molecular weights [71].

Apart from that, there was also RS which was ascribed as a phase that was insoluble in either water or acetone. As can be seen from Figure 5, the RS yield showed a continuous reducing trend with every increased temperature. This was due to the thermal degradation that caused the carbon content in SB solids gradually hydrolyzed and pyrolyzed throughout the reaction temperature range. A huge dropped of RS yield were also observed at temperature as low as $180{ }^{\circ} \mathrm{C}(70 \%$ (inner) and $50 \%$ (outer)). Meanwhile, due to the extreme degradation of biomass constituents into smaller compounds at higher temperature, significant reduction of SB was recorded at $320{ }^{\circ} \mathrm{C}$, with the yield of 0.065 and $0.249 \mathrm{~g} / \mathrm{g}$-dry SB for inner and outer layer respectively. Nonetheless, RS yield obtained from outer layer was more apparent as compared to the inner layer throughout the reaction temperature. This trend is expected based on the higher lignin content possessed by the outer layer (refer Table 1). The result obtained was further supported by Zhong and Wei [72], who found that the char formation was enhanced with the high amount of lignin through his comparative study of various wood samples.

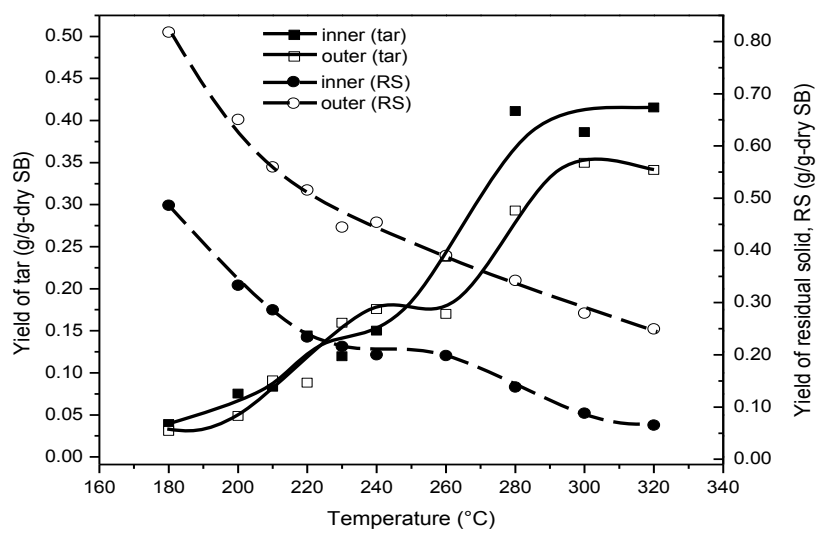

Figure 5 Effect of reaction temperature on yield of tar and residual solid (Reaction time: $5 \mathrm{~min}$ )

\section{CONCLUSIONS}

SCW treatment as a green and environmentally benign technology has successfully been applied on SB to produce valuable materials. It was apparent that $\mathrm{SCW}$ temperature substantially influenced the yields of variety products produced. The experimental TOC confirmed that the hemi- and cellulosic parts of SB different layers were hydrolyzed and efficiently converted to water-soluble compounds. A significantly higher TOC and TS yields were obtained from 
inner than the outer layer at $210^{\circ} \mathrm{C}, 0.40$ and $0.67 \mathrm{~g} / \mathrm{g}$-dry SB respectively. Both layers had generated similar types of monosaccharides and inner layer showed extremely better yield of glucose, xylose and arabinose with the values of $0.125,0.123$ and $0.019 \mathrm{~g} / \mathrm{g}$-dry SB, respectively within $5 \mathrm{~min}$. There were six organic acids in notable amounts were identified from decomposition of SB at higher temperature which helped in auto-catalyzing the solubility of SB under SCW conditions. A huge dropped of solid SB was observed at temperature as low as $180{ }^{\circ} \mathrm{C}(70 \%$ (inner) and $50 \%$ (outer)) and a considerable yield of tar was produced at elevated temperature $>280{ }^{\circ} \mathrm{C}$. SB inner layer is more susceptible to SCW treatment as compared to outer layer and has shown a promising source to be utilized for a variety of value-added substances i.e. sugars, organic acids and tar.

\section{ACKNOWLEDGMENT}

Authors are grateful for the fund received from Putra Grant-Putra Graduate Initiative (GP-IPS 9536400) from Universiti Putra Malaysia

\section{REFERENCES}

[1] Ozturk, I., Irmak, S., Hesenov, A., and Erbatur, O., 2010, "Hydrolysis of kenaf (Hibiscus cannabinus L .) stems by catalytical thermal treatment in subcritical water," Biomass Bioenerg., 34, pp. 1578-1585.

[2] Isikgor, F. H., and Becer, C. R., 2015, "Lignocellulosic biomass: A sustainable platform for the production of bio-based chemicals and polymers," Polym. Chem., 6(25), pp. 4497-4559.

[3] Xiu, S., and Shahbazi, A., 2012, "Bio-oil production and upgrading research: A review," Renewable and Sustainable Energy Reviews., 16(7), pp. 4406-4414.

[4] Nanda, S., Kozinski, J. A., and Dalai, A. K., 2016, "Lignocellulosic biomass : A review of conversion technologies and fuel products," Current Biochemical Engineering., 3(1), pp. 24-36.

[5] Anwar, Z., Gulfraz, M., and Irshad, M., 2014, “Agroindustrial lignocellulosic biomass a key to unlock the future bio-energy : A brief review," J. Rad. Res. Appl Sc., 7, pp. 163-173.

[6] Zhu, G., Zhu, X., Fan, Q., and Wan, X., 2011, "Recovery of biomass wastes by hydrolysis in subcritical water," Resour. Coserv. Recy., 55(4), pp. 409416.

[7] Ethaib, S., Omar, R., Mazlina, M. K. S., Radiah, A. B. D., and Syafiie, S., 2016, "Microwave-assisted dilute acid pretreatment and enzymatic hydrolysis of sago palm bark," BioResources., 11(3), pp. 5687-5702.

[8] Kin, Y., Sadhukhan, J., Siew, K., and Ng, D. K. S., 2015, "Techno-economic evaluations for feasibility of sago-based biorefinery, Part 1 : Alternative energy systems," Chem. Eng. Res. Des., 107, pp. 263-279.
[9] Kannan, S. T., Ahmed, A., and Ani, F., 2013, "Energy efficient microwave irradiation of sago bark waste (SBW) for bioethanol production," Adv. Mater. Res., 701, pp. 249-253.

[10] Mohamad, N. L., Kamal, S. M. M., Abdullah, N., and Ismail, I., 2013, "Evaluation of fermentation conditions by candida tropicalis for xylitol production from sago trunk cortex," BioResources, 8(2), pp. 2499-2509.

[11] Bhagwat, S., Ratnaparkhe, S., and Kumar, A., 2015, "Biomass pre-treatment methods and their economic viability for efficient production of biofuel," $\mathrm{Br}$. Biotechnol. J., 8(2), pp. 1-17.

[12] Alejandra, A.-R., Romaní, A., Rodríguez-Jasso, R. M., Aguilar, C. N., Garrote, G., and Ruiz, H. A., 2017, "Microwave heating processing as alternative of pretreatment in second-generation biorefinery: An overview," Energ Convers Manage, 136, pp. 50-65.

[13] Zhu, G., Zhu, X., Fan, Q., and Wan, X., 2011, "Production of reducing sugars from bean dregs waste by hydrolysis in subcritical water," J. Anal. Appl. Pyrolysis, 90, pp. 182-186.

[14] Wiboonsirikul, J., Mori, M., Khuwijitjaru, P., and Adachi, S., 2013, "Properties of extract from okara by its subcritical water treatment," Int. J. Food Prop, 16(5), pp. 974-982.

[15] Mohan, M., Banerjee, T., and Goud, V. V., 2015, "Hydrolysis of bamboo biomass by subcritical water treatment," Bioresour. Technol., 191, pp. 244-252.

[16] Asghari, F. S., and Yoshida, H., 2010, "Conversion of Japanese red pine wood (Pinus densiflora) into valuable chemicals under subcritical water conditions," Carbohydr. Res., 345(1), pp. 124-131.

[17] Abd Rahman, K. A. A., 2005, "Utilizing sago (Metroxylon spp) bark waste for value added products," Proc. - 4th International Symposium on Environmentally Conscious Design and Inverse Manufacturing, Eco Design, 2005, pp. 102-106.

[18] Chong, K. H., Law, P. L., Rigit, A. R. H., Baini, R., and Shanti, F. S., 2014, "Sago bark as renewable energy," UNIMAS e-Journal of Civil Engineering, 5(2), pp. 2934.

[19] Kurnin, N. A. A., Ismail, M. H. S., Yoshida, H., and Izhar, S., 2016, "Recovery of Palm Oil and Valuable Material from Oil Palm Empty Fruit Bunch by Subcritical Water,” J. Oleo Sci., 65(4), pp. 283-289.

[20] Hashim, R., Nadhari, W. N. A. W., Sulaiman, O., Kawamura, F., Hiziroglu, S., Sato, M., Sugimoto, T., Seng, T. G., and Tanaka, R., 2011, "Characterization of raw materials and manufactured binderless particleboard from oil palm biomass," Mater. Des., 32, pp. 246-254.

[21] Ilyas, R. A., Sapuan, S. M., and Ishak, M. R., 2018, "Isolation and characterization of nanocrystalline cellulose from sugar palm fibres (Arenga Pinnata)," 
Carbohydr. Polym., 181, pp. 1038-1051.

[22] Pourali, O., Salak, F., and Yoshida, H., 2009, "Subcritical water treatment of rice bran to produce valuable materials," Food Chem., 115(1), pp. 1-7.

[23] Abdelmoez, W., and Yoshida, H., 2006, "Simulation of fast reactions in batch reactors under sub-critical water condition," AIChe J., 52(10), pp. 3600-3611.

[24] Yoshida, H., Terashima, M., and Takahashi, Y., 1999, "Production of organic acids and amino acids from fish meat by sub-critical water hydrolysis," Biotechnol. Progr., 15, pp. 1090-1094.

[25] Awaluddin, S. A., Thiruvenkadam, S., Izhar, S., Hiroyuki, Y., Danquah, M. K., and Harun, R., 2016, "Subcritical water technology for enhanced extraction of biochemical compounds from Chlorella vulgaris," Biomed Res. Int., pp. 1-10.

[26] Nielsen, S. S., 2010, "Phenol-sulfuric acid method for total carbohydrates," Food Analysis Laboratory Manual, 2010, pp. 47-53.

[27] Yoshida, H., and Tavakoli, O., 2004, "Subcritical water hydrolysis treatment for waste squid entrails and production of amino acids , organic acids , and fatty ...,", J. Chem. Eng. Jpn., 37(2), pp. 253-260.

[28] Mohan, D., Pittman, C. U., and Steele, P. H., 2006, "Pyrolysis of wood/biomass for bio-oil : A critical review," Energy Fuels, 20(3), pp. 848-889.

[29] Smith, K., 2015, The sago palm: The food and environmental challenges of the 21 st century. 2015.

[30] Hoch, G., Richter, A., and Körner, C., 2003, "Nonstructural carbon compounds in temperate forest trees," Plant, Cell Environ., 26, pp. 1067-1081.

[31] Pandey, M. P., and Kim, C. S., 2011, "Lignin depolymerization and conversion : A review of thermochemical methods," Chem. Eng. Technol., 34(1), pp. 29-41.

[32] Mohamad, N. L., Kamal, S. M. M., and Abdullah, A. G. L., 2011, "Optimization of xylose production from sago trunk cortex by acid hydrolysis," African Journal of Food Science and Technology, 2(5), pp. 102-108.

[33] Lachos-perez, D., Tompsett, G. A., Guerra, P., Timko, M. T., Rostagno, M. A., Martínez, J., and Forstercarneiro, T., 2017, "Sugars and char formation on subcritical water hydrolysis of sugarcane straw," Bioresour. Technol., 243, pp. 1069-1077.

[34] Szczerbowski, D., Pitarelo, A. P., Filho, A. Z., and Ramos, L. P., 2014, "Sugarcane biomass for biorefineries : Comparative composition of carbohydrate and non-carbohydrate components of bagasse and straw," Carbohydr. Polym., 114, pp. 95101.

[35] Karimi, K., and Taherzadeh, M. J., 2016, “A critical review of analytical methods in pretreatment of lignocelluloses : Composition, imaging, and crystallinity," Bioresour. Technol., 200, pp. 10081018.

[36] Kong, L., Li, G., Zhang, B., He, W., and Wang, H., 2008, "Hydrogen production from biomass wastes by hydrothermal gasification," Energy Sources, Part A: Recovery, Utilization, and Environmental Effects, 30(13), pp. 1166-1178.

[37] Toor, S., Rosendahl, L., and Rudolf, A., 2011, "Hydrothermal liquefaction of biomass : A review of subcritical water technologies," Energy, 36(5), pp. 2328-2342.

[38] Prado, J. M., Lachos-perez, D., Forster-carneiro, T., and Rostagno, M. A., 2015, "Sub- and supercritical water hydrolysis of agricultural and food industry residues for the production of fermentable sugars : A review," Food Bioprod Process, 98, pp. 95-123.

[39] Sorek, N., Yeats, T. H., Szemenyei, H., Youngs, H., and Somerville, C. R., 2014, "The implications of lignocellulosic biomass chemical composition for the production of advanced biofuels," Bioscience, 64(3), pp. 192-201.

[40] Rogalinski, T., Liu, K., Albrecht, T., and Brunner, G., 2008, "Hydrolysis kinetics of biopolymers in subcritical water," J. Supercrit. Fluids, 46, pp. 335 341 .

[41] Kim, Y., Kreke, T., Mosier, N. S., and Ladisch, M. R., 2014, "Severity factor coefficients for subcritical liquid hot water pretreatment of hardwood chips," Biotechnol. Bioeng., 111(2), pp. 254-263.

[42] Lachos-Perez, D., Brown, A. B., Mudhoo, A., Martinez, J., Timko, M. T., Rostagno, M. A., and Forster-Carneiro, T., 2017, “Applications of subcritical and supercritical water conditions for extraction, hydrolysis, gasification, and carbonization of biomass : A critical review," Biofuel Res. J., 14, pp. 611-626.

[43] Abdelmoez, W., Nage, S. M., Bastawess, A., Ihab, A., and Yoshida, H., 2014, "Subcritical water technology for wheat straw hydrolysis to produce value added products," J. Clean. Prod., 70, pp. 68-77.

[44] Prado, J. M., Carneiro, T. F., Gigo, M. A., Celestrino, R. C. C., Follegatti-Romero, L. A., Filho, F. M., and Meireles, M. A. A., 2013, "Subcritical water hydrolysis of sugarcane bagasse," Proc. III Iberoamerican Conference on Supercritical Fluids Cartagena de Indias (Colombia), 2013, pp. 1-9.

[45] Klinchongkon, K., Khuwijitjaru, P., Wiboonsirikul, J., and Adachi, S., 2015, "Extraction of oligosaccharides from passion fruit peel by subcritical water treatment," J. Food Process Eng., pp. 1-8.

[46] Mohan, M., Timung, R., Deshavath, N. N., Banerjee, T., V.Goud, V., and V. Dasu, V., 2015, “Optimization and hydrolysis of cellulose under subcritical water treatment for the production of total reducing sugars," 
The Royal Society Chemistry, 5, pp. 103265-103275.

[47] Jintana, W., and Shuji, A., 2008, "Extraction of functional substances from agricultural products or byproducts by subcritical water treatment: A review," Food Sci.Technol. Res., 14(4), pp. 319-328.

[48] Kamio, E., Takahashi, S., Noda, H., Fukuhara, C., and Okamura, T., 2006, "Liquefaction of cellulose in hot compressed water under variable temperatures," Ind. Eng. Chem. Res., 45, pp. 4944-4953.

[49] Matsunaga, M., Matsui, H., Otsuka, Y., and Yamamoto, S., 2008, "Chemical conversion of wood by treatment in a semi-batch reactor with subcritical water," J. Supercrit. Fluids, 44, pp. 364-369.

[50] Lu, X., and Saka, S., 2010, "Hydrolysis of Japanese beech by batch and semi-flow water under subcritical temperatures and pressures," Biomass Bioenerg., 34(8), pp. 1089-1097.

[51] Kamio, E., Sato, H., Takahashi, S.,Noda, H., Fukuhara, C., and Okamura, T., 2008, "Liquefaction kinetics of cellulose treated by hot compressed water under variable temperature conditions," J. Mater. Sci., 43, pp. 2179-2188.

[52] Brummer, Y., and Cui, S. W., 2015, "Understanding carbohydrate analysis," Food carbohydrates: Chemistry, physical properties and applications, Chap 2, pp. 67-72.

[53] Asif, M., 2009, "Sustainability of timber, wood and bamboo in construction," Sustainability of construction materials, Woodhead Publishing Limited, Glasgow Caledonian University, UK, Chap 2, pp. 31-54.

[54] Jones, D., Ormondroyd, G. O., Curling, S. F., Popescu, C., and Popescu, M., 2017, "Chemical compositions of natural fibres," Advanced High Strength Natural Fibre in Construction, 2017, pp. 23-58.

[55] Maki-Arvela, P., Salmi, T., Holmbom, B., Willfor, S., and Murzin, D. Y., 2011, "Synthesis of sugars by hydrolysis of hemicelluloses: A review," Chem. Rev., 111, pp. 5638-5666.

[56] Moller, M., Harnisch, F., and Schroder, U., 2013, "Hydrothermal liquefaction of cellulose in subcritical water - the role of crystallinity on the cellulose," RSC Advcances, 3, pp. 11035-11044.

[57] Yu, Y., and Wu, H., 2010, "Significant differences in the hydrolysis behavior of amorphous and crystalline portions within microcrystalline cellulose in hotcompressed water," Ind. Eng. Chem. Res., 49, pp. 3902-3909.

[58] Fan, S., Zhang, P., Li, F., Jin, S., Wang, S., and Zhou, S., 2016, "A review of lignocellulose change during hydrothermal pretreatment for bioenergy production," Curr. Org. Chem., 20, pp. 1-11.

[59] Lin, R., Cheng, J., Ding, L., Song, W., Qi, F., Zhou, J., and Cen, K., 2015, "Subcritical water hydrolysis of rice straw for reducing sugar production with focus on degradation by-products and kinetic analysis," Bioresour. Technol., 186, pp. 8-14.

[60] Ethaib, S., Omar, R., Mazlina, M. K. S., Radiah, A. B. D., Syafiie, S., and Harun, M. Y., 2016, "Microwaveassisted pretreatment of sago palm bark," J. Wood Chem. Technol., 0, pp. 1-17.

[61] Prado, J. M., Forster-Carneiro, T., Rostagno, M. A., Follegatti-Romero, L. A., Maugeri Filho, F., and Meireles, M. A. A., 2014, "Obtaining sugars from coconut husk, defatted grape seed, and pressed palm fiber by hydrolysis with subcritical water," J. Supercrit. Fluids, 89, pp. 89-98.

[62] Kumar, S., and Gupta, R. B., 2009, "Biocrude production from switchgrass using subcritical water," Energy Fuels, 23, pp. 5151-5159.

[63] Wang, Y., Yao, G., and Jin, F., 2014, "Hydrothermal conversion of cellulose into organic acids with a $\mathrm{CuO}$ oxidant," Application of Hydrothermal Reactions to Biomass Conversion, Green Chemistry and Sustainable Technology, Chap 2, pp. 31-59.

[64] Jin, F., Zhou, Z., Enomoto, H., Moriya, T., and Higashijima, H., 2004, "Conversion mechanism of cellulosic biomass to lactic acid in subcritical water and acid-base catalytic effect of subcritical water," Chem. Lett., 33(2), pp. 3-4.

[65] Yoshida, H., and Katayama, Y., 2004, "Production of useful substances from wood wastes by sub-critical water hydrolysis," Proc. Asian Pacific Confederation of Chemical Engineering congress program and abstracts, pp. 1-9.

[66] Demirbas, A., 2008, "Products from lignocellulosic materials via degradation processes," Energy Sources, Part A: Recovery, Utilization, and Environmental Effects, 30, pp. 27-37.

[67] Zazalli, M., Yoshida, H., Halim, M., Ismail, S.,Sabli, N.,and Izhar, S., 2017, "Recovery of oil from waste palm kernel cake by sub-critical water," Int. J. Appl. Eng. Res., 12(24), pp. 14574-14579.

[68] Kumar, S., and Gupta, R. B., 2008, "Hydrolysis of microcrystalline cellulose in subcritical and supercritical water in a continuous flow reactor," Ind Eng. Chem. Res., 47, pp. 9321-9329.

[69] Pavloviè, I., Knez, Ý., and Škerget, M., 2013, "Hydrothermal reactions of agricultural and food processing wastes in sub- and supercritical water : A review of fundamentals, mechanisms and state of research," J. Agric. Food Chem., 61(34), pp. 80038025 .

[70] Peterson, A. A., Vogel, F., Lachance, R. P., Froling, M., Antal, M. J., and Tester, J. W., 2008, "Thermochemical biofuel production in hydrothermal media : A review of sub- and supercritical water technologies," Energy Environ. Sci., 1, pp. 32-65. 
International Journal of Engineering Research and Technology. ISSN 0974-3154, Volume 13, Number 1 (2020), pp. 1-11

(C) International Research Publication House. https://dx.doi.org/10.37624/IJERT/13.1.2020.1-11

[71] Savou, V., Grause, G., Kumagai, S., Saito, Y., and Kameda, T., 2018, "Pyrolysis of sugarcane bagasse pretreated with sulfuric acid," Journal of the Energy Institute, 30, pp. 1-9.

[72] Zhong, C., and Wei, X., 2004, "A comparative experimental study on the liquefaction of wood," Energy, 29, pp. 1731-1741. 